\title{
Pre-operative Cardiovascular Evaluation in elective Noncardiac Surgery, Risk Scores, and Managerial Insight for Patients with Different Cardiac Morbidities
}

\author{
Mireille Nasr ${ }^{1}$, Mikhael Kossaify ${ }^{2}$, Antoine Kossaify ${ }^{3 *}$ \\ ${ }^{1}$ Department of Critical Care, Anesthesia Division, University Hospital Notre Dame des Secours, Byblos, Lebanon, ${ }^{2}$ Department \\ of Cardiology, School of Medicine, USEK, University Hospital Notre Dame des Secours, Byblos, Lebanon, ${ }^{3}$ Department of \\ Cardiology, Cardiology Division, University Hospital Notre Dame des Secours, Byblos, Lebanon
}

Edited by: Slavica Hristomanova-Mitkovska Citation: Nasr M, Kossaify M, Kossaify A. Pre-operative Cardiovascular Evaluation in elective Noncardiac Surgery, Different Cardiac Morbidities. Open Access Maced Med Sci. 2020 Apr 28; 8(F):41-51. https://doi.org/10.3889/ oamjms.2020.3372 Keywords: Anesthesia; Cardiac; Pre-operative Complications; Surgery; Awareness Correspondence: Antoine Kossaify, Department of Cardiology, Cardiology Division, University Hospita Notre Dame des Secours, Byblos, Lebanon, Phone: +9613232192. E-mail: antoinekossaify@yahoo.com Received: 15-Aug-2019 Revised: 01-Jan-2020

Copyright: $\odot 2020$ Mireille Nasr, Mikhael Kossaify
Antoine Kossaify
This research did not receive any financial support

Copyright: $\odot 2020$ Mireille Nasr, Mikhael Kossaify
Antoine Kossaify
This research did not receive any financial support Funding: This research did not receive any financial support
Competing Interests: The authors have declared that no competing interests exis pen Access: This is an open-access article distributed under the terms of the Creative Commons Attribution-

\begin{abstract}
Cardiac pre-operative evaluation must aim to estimate the perioperative cardiovascular risk, taking into consideration the individual clinical setting along with the type of surgery. Pre-operative assessment and management comprise evaluation of risk scores and the potential performance of some paraclinical tests to better prepare the patient for surgery. Pain management, adequate hydration, and thromboembolic prophylaxis constitute the main axis to decrease perioperative cardiovascular complications; moreover, the presence of previous cardiac conditions along with hypersympathetic activity is involved in a significant percentage of perioperative morbidity. Patients with minimal perioperative risk may not require systematically a cardiology consultation, whereas patients with moderate or high surgical risk often require a multidisciplinary approach for better perioperative management. The use of paraclinical tests to evaluate cardiac condition, such as cardiac biomarkers, echocardiogram, and other noninvasive or invasive cardiac testing, should be tailored on a case-by-case basis. Such professional practice aims to limit unnecessary healthcare expenses without compromising clinical outcome. Pre-operative surgical risk is not only based on cardiovascular condition but also on other factors and comorbidities such as diabetes, renal function, and functional status. In this regard, the role of the anesthesiologist is essential to evaluate the pre-operative risk (mild, moderate, or high), also to manage the whole perioperative period.
\end{abstract}

\section{Introduction}

The terms "pre-operative consultation" were mentioned in medical literature more than 60 years ago [1], [2]. One of the first attempts to stratify surgical perioperative risk was performed by Goldman et al. in 1977 [3].

Perioperative mortality in noncardiac surgery is estimated between $1 \%$ and $5 \%$ and nearly onethird of this mortality is consecutive to cardiovascular complications [4], [5]. Cardiac complications occur more frequently in patients with cardiac conditions such as ischemic heart disease, left ventricular dysfunction, valvular heart disease, or arrhythmias [6]. Demographics of patients undergoing surgery show a trend toward an increasing number of elderly patients and associated comorbidities; moreover, cardiovascular disease is the most frequent comorbidity in elderly patients presenting for general surgery [6], [7].

Morbidity and mortality after noncardiac surgery vary considerably among different facilities and countries, and accordingly, there must be significant human and organizational factors at play explaining these discrepancies [8], [9]. Nowadays, there are significant discrepancies regarding the use of pre-operative cardiac paraclinical testing, especially in a context of quite common restricted medical budget [10], [11]. For instance, there is substantial medical discrepancy in daily practice regarding the use of cardiac pre-operative consultations, the extent of use of pre-operative paraclinical tests, the type of anesthesia, the methods used for postoperative pain control, hemodynamic monitoring, and sympathoadrenergic contraregulation [9], [12]. In addition, the use of risk scores in daily practice is insufficient or sometimes absent, and the collaboration between anesthesiologists, cardiologists, surgeons, and intensivists is often insufficient and such collaboration is of utmost importance to decrease perioperative morbidity in high-risk patients [6].

In this regard, the task of the cardiologist, together with the anesthesiologist, is of utmost importance to accurately assess risks in patients undergoing 
noncardiac surgeries and to avoid or minimize adverse cardiovascular events. In this study, we sought to emphasize the importance of pre-operative cardiac risk stratification, with a focus on the role of both cardiologist and anesthesiologist, along with a multidisciplinary approach especially in moderate or high-risk patients, aiming to expand awareness for better perioperative management and outcome in elective noncardiac surgery.

\section{Methods}

A MEDLINE/PubMed search was performed to identify relevant articles using the following keywords: "Perioperative morbidity; risk scores" yielding 679 articles and "pre-operative cardiac risk assessment" yielding 4003 articles. Furthermore, there was manual search for relevant guidelines, also manual search was performed to find relevant articles from the reference lists of obtained articles. Topics discussed in this article involve elective noncardiac surgery, including endoscopic procedures; therefore, articles related to emergent surgery or cardiac surgery were excluded. Similarly, case reports and articles that were not in English were excluded, also those that focused solely on pediatric or gyneco-obstetrical population were excluded from the study. No specific date limit of publication was considered, though we focused on the most recent publications. As a result, 287 articles were selected and overviewed for suitability, and only 78 articles found relevant were selected. Figure 1 illustrates the process of selection of different articles.

\section{Physiopathology of perioperative cardiac}

events

Perioperative medicine is regarded as an emerging field in medicine, and it is defined as the practice of patient-centered, multidisciplinary and integrated medical approach from the moment of contemplation for surgery until full recovery, an approach that focuses on optimizing patients well-being and reducing perioperative morbidity and mortality [13]. The perioperative period consists practically of the immediate in-hospital pre-operative interval, together with the intraoperative and the in-hospital postoperative intervals; however, in many studies, the postoperative period was considered as such until 30 days post-surgery [6].

The risk of perioperative complications depends broadly on the patient general condition, the presence of comorbidities, and the characteristics of the surgical procedure (type, magnitude, urgency, and duration). In general, operative risk can be classified as low, intermediate, or high (Table 1) [6], [14].

Many factors interfere to affect the occurrence of cardiac complications during or after noncardiac surgery, and these factors are mainly divided into patient-related factors (general status, functional capacity, and cardiac comorbidities), and procedure-related factors (type of surgery, pre-operative preparation, etc.) [15] (Figure 2).

The presence of previous cardiac history is a significant factor predisposing to perioperative cardiac events; hypertension, heart failure, coronary artery disease, valvular heart disease, and cardiac arrhythmia

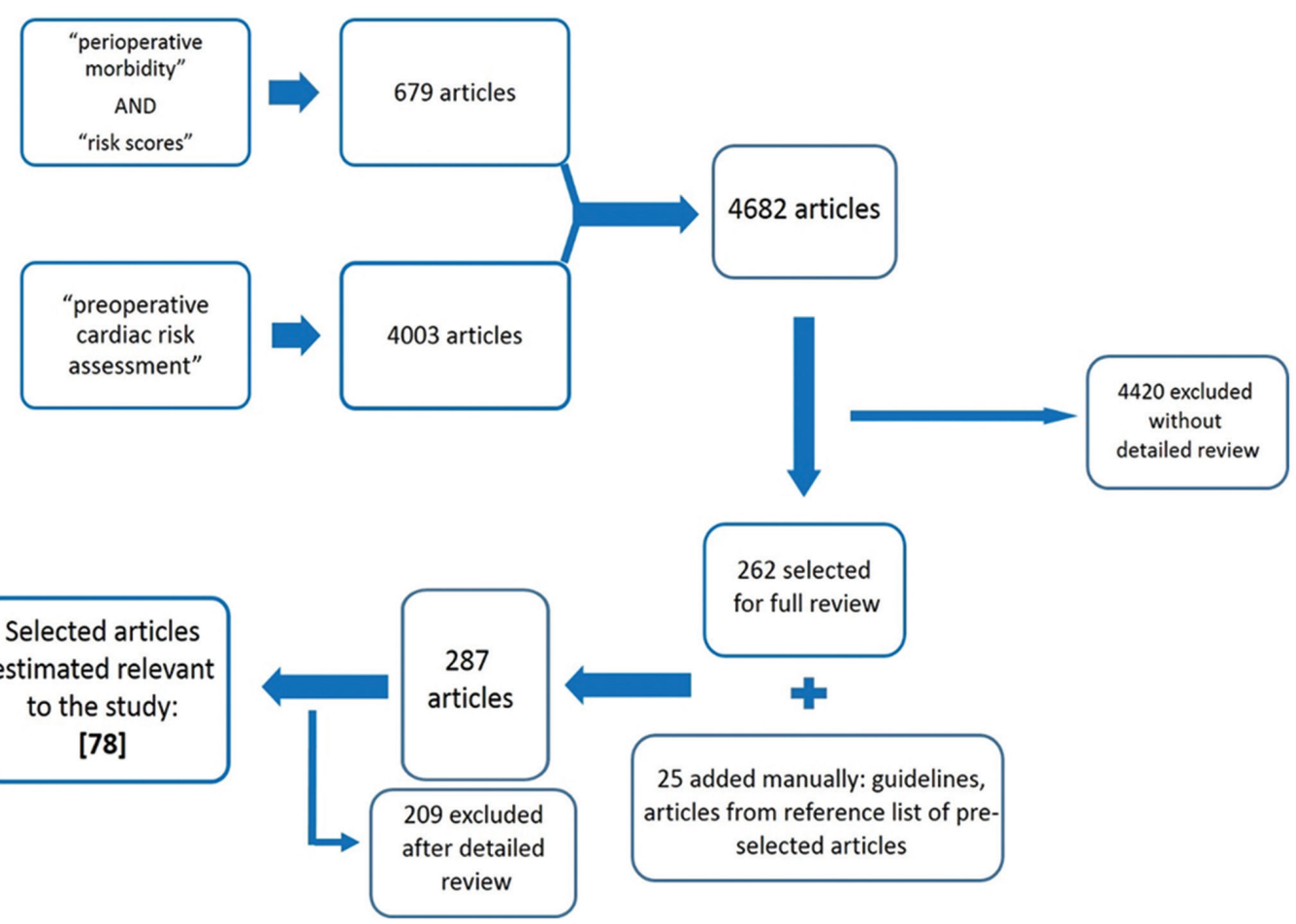

Figure 1: Algorithm showing the process of articles selection 
Table 1: Procedural cardiac risk. Different cardiac risks (low, intermediate, and high) associated with different types of surgeries (adapted from Kristensen et al.) [8]

\begin{tabular}{lll}
\hline Low cardiac risk & Intermediate cardiac risk & High cardiac risk \\
\hline Endoscopic procedures & Head and neck surgery & Emergent surgery on patients above \\
& & 75-year-old \\
Cataract & Prostate surgery & Aortic and major vascular surgery \\
Breast surgery & Intrathoracic surgery & Peripheral surgery \\
Skin and subcutaneous & Intraperitoneal surgery & Surgery with long procedural \\
tissue & & duration \\
& Orthopedic surgery & Surgery with significant fluid shifts \\
& Carotid surgery & Surgery with significant blood loss \\
\hline
\end{tabular}

form the main cardiac conditions that must be recognized and managed in the perioperative period [6].

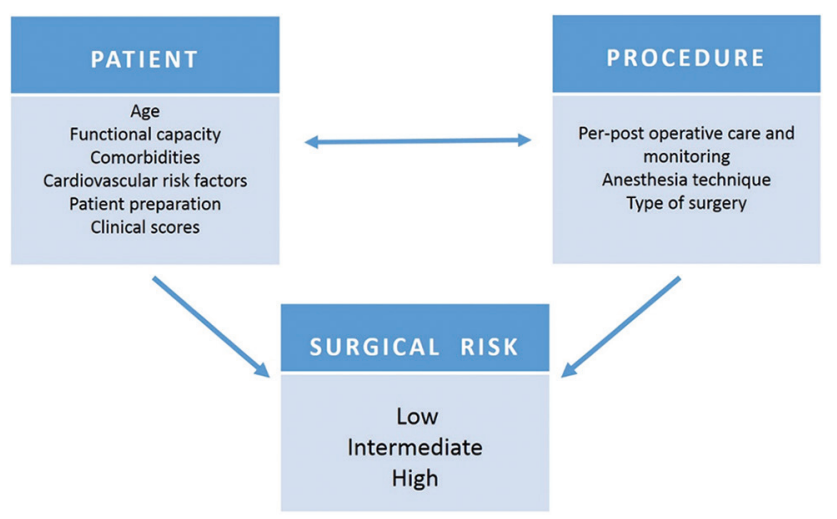

Figure 2: Surgical risk. Surgical risk (low, intermediate, and high) associated with different patients and different procedural parameters [14], [15].

Any interventional procedure may provoke a reaction of the organism initiated by pain, psychological stress, and tissue injury. Moreover, the perioperative period is usually marked by a bedridden status, especially after major surgeries which are usually followed by excess pain and long hospital stay. In addition, during surgery, there is a potential change in body temperature, fluid shifts, and blood loss. All these factors contribute to increase sympathetic nerve tone leading to an increase in myocardial oxygen demand along with a trend to increased thrombogenicity, thus predisposing to general and to cardiovascular complications [16], [17], [18]. The type of surgery and the form of anesthesia that is used (general, locoregional, and neuraxial) affects perioperative morbidity. Less invasive anesthetic techniques are known to reduce morbidity and mortality in high-risk patients (Figure 3) [15], [19]. Table 1 illustrates the cardiac risk associated with different types of surgeries.

Cardiac morbidities, other co-morbidities, type of surgery, type of anesthesia, functional status

pain, stress, tissue injury, bedridden status, fluid shift, blood loss, hypoxia

Thrombogenicity- Hypersympathetic tonus

Perioperative morbidity/mortality

Figure 3: Different factors and physiopathology involved in perioperative morbidity/mortality [14], [15], [16].

\section{Risk scores}

Risk scores may provide a broad predictive value regarding cardiac risk in the perioperative period. Although they do not yield a perfect predictive value regarding morbidity and mortality, they help to indicate whether the patient has a low, intermediate, or high perioperative risk. Historically, the main risk scores were developed by Goldman et al., Detsky et al., and Lee et al. in 1977, 1986, and 1999 respectively [3], [20], [21]. The Lee index also called "revised cardiac risk index" (RCRI) calculation is based on six predictors: Type of surgery, history of ischemic heart disease or heart failure, history of cerebrovascular disease, diabetes mellitus with insulin therapy, and a creatinine value $>2 \mathrm{mg} / \mathrm{dL}$ [21]. Table 2 illustrates the different parameters comprised in the RCRI and the associated surgical risk.

Table 2: RCRI and the associated complication risk (adapted from Lee et al.) [21]

\begin{tabular}{|c|c|c|}
\hline \multicolumn{2}{|c|}{ Lee score, RCRI } & Points \\
\hline \multicolumn{2}{|c|}{ High-risk surgery } & 1 \\
\hline \multicolumn{2}{|c|}{ Coronary artery disease } & 1 \\
\hline \multicolumn{2}{|c|}{ Congestive heart failure } & 1 \\
\hline \multicolumn{2}{|c|}{ History of cerebrovascular disease } & 1 \\
\hline \multicolumn{2}{|c|}{ Diabetes mellitus on insulin therapy } & 1 \\
\hline \multicolumn{2}{|c|}{ Pre-operative serum creatinine $>2 \mathrm{mg} / \mathrm{dL}$} & 1 \\
\hline Risk class & Points & Complication risk \% \\
\hline Very low & 0 & 0.4 \\
\hline Low & 1 & 0.9 \\
\hline Intermediate & 2 & 6.6 \\
\hline High & $\geq 3$ & 11.0 \\
\hline
\end{tabular}

The RCRI aims to predict post-operative pulmonary edema, myocardial infarction, ventricular fibrillation or cardiac arrest, and complete heart block. The RCRI used to be considered a very useful cardiacrisk prediction index in noncardiac surgery; however, it was developed years ago and many progressions occurred since then regarding diagnosis and management of cardiovascular diseases [7].

More recently was developed a risk calculator based on the National Surgical Quality Improvement Program and it is based on five predictors of perioperative myocardial infarction and/or cardiac arrest: Type of surgery, functional status, elevated creatinine $(>1.5 \mathrm{mg} / \mathrm{dL})$, and American Society of Anesthesiologists class and age [22]

In clinical practice, risk scores are not implemented unanimously, also these scores should not impose a predetermined management decision systematically, they should rather be regarded as one of the multiple pieces of the puzzle in the pre-operative context. In addition, these risk scores were developed years ago, and none has a perfect predictive value; in this regard, they could be used as complementary risk predictors in a changing medical world [7], [8]. Moreover, they should be used to optimize the pre-operative risk stratification, helping to reduce unnecessary pre-operative paraclinical tests and to apply tailored perioperative management [8]. Figure 2 illustrates the surgical risk associated with different patients and procedural parameters. 


\section{Pre-operative cardiovascular evaluation}

In general, history, physical examination, and electrocardiogram (EKG) along with standard laboratory testing and chest-X-ray form the routine pre-operative workup for most patients. Patients considered at low perioperative cardiac risk can usually be operated without further testing, whereas more extensive testing may be required in patients considered at intermediate or high perioperative risk [6].

Patients with pre-existing cardiac disease or those with significant cardiovascular risk factors have a significantly higher risk of perioperative cardiac events, and the medical team should concentrate on the consistent use of all preventive and therapeutic measures available to decrease the perioperative risk [5], [23]. More extensive paraclinical testing may be required on a case-by-case decision [8].

For instance, noninvasive or invasive cardiac testing such as pre-operative resting echocardiography, stress echo, or coronary angiogram is unnecessary in low-risk patients and might be considered according to clinical settings in intermediate and high-risk patients [11], [24]. Similarly, advanced biological testing (i.e., cardiac biomarkers) is required on a case-by-case basis [25]. However, in real practice, it is sometimes difficult to trace a straight line between low and intermediate-risk patients or between intermediate and high-risk patients and therefore the use of risk scores is helpful in this regard [21], [22].

Of note, the following pre-operative tests results are considered as markers of elevated cardiac morbidity/mortality: Abnormal resting EKG, malignant ventricular arrhythmia or high grade atrioventricular conduction disease, left ventricular ejection fraction $\leq 35 \%$, abnormal stress test suggesting myocardial ischemia, positive stress echo, positive cardiac troponin test, abnormal BNP levels, and high $\mathrm{C}$-reactive protein levels [8], [26], [27], [28].

\section{Cardiac conditions}

Cardiac pre-operative evaluation includes an assessment of the presence and severity of any cardiovascular condition and/or cardiovascular risk factors. Moreover, cardiac assessment must comprise evaluation of the patient general condition, including mainly functional capacity, respiratory, renal, and endocrine function, given the interaction of these functions with the cardiovascular system. The main cardiac conditions to screen and evaluate consist of hypertension, heart failure, coronary artery disease, valvular heart disease, and cardiac arrhythmia [8], [29].

\section{Hypertension}

Anesthesia and surgery should not be canceled in case of uncomplicated pre-operative hypertension; however, elective surgery may be postponed in patients with severe hypertension (i.e. systolic blood pressure $>180 \mathrm{mmHg}$ or diastolic blood pressure $>110 \mathrm{mmHg}$ ), given that uncontrolled hypertension increases risks of perioperative complications [30]. Of note, the white coat effect yielding pseudohypertension in this context should be evoked in patients with new-onset undiagnosed hypertension; in this regard, it is important to validate the diagnosis of hypertension by repetitive measurements, while considering automated devices if necessary.

Pre-operative blood pressure control may be achieved with any anti-hypertensive therapy, with a special preference to beta-blockers given their proven perioperative benefit [31]; in this regard, all antihypertensive drugs may be held - if justified - on the morning of the surgery, except for beta-blockers which have proven a longer clinical benefit when continued during the post-operative period [30], [31]. Of note, postsurgical pain may exacerbate a relatively stable blood pressure and management must take into account sedation and antalgics besides anti-hypertensive therapy.

\section{Heart failure}

The prevalence of heart failure is higher with advanced age, the age during which the rate of cardiac and noncardiac surgery is higher [32]. The presence of heart failure increases cardiac perioperative risks according to validated risk scores [3], [20], [21]. Increased BNP levels in the pre-operative period predisposes to higher per- and post-operative cardiac morbidity and mortality [33]; similarly, a left ventricular ejection fraction $\leq 35 \%$ and/or the presence of diastolic dysfunction with elevated left ventricular filling pressure are predictive of adverse outcome in the post-operative phase [34], [35]. Exacerbation of heart failure in the perioperative period may result from change in medications, also from pain and surgical adrenergic stress, leading to the excessive workload on a failing myocardium [36]. Of note, any fluid replacement should be carefully administered and adapted to the hemodynamic condition to avoid volume overload [37]. In view of this, a flexible diuretic regimen must be adopted in the perioperative period to avoid congestion or volume depletion in patients with heart failure. Surgical procedures with intermediate or high risks should be delayed (unless urgent) in patients with decompensated or unstable heart failure until better preparation and stabilization of the hemodynamic condition [38].

\section{Coronary artery disease}

Coronary artery disease represents a significant cause of morbidity and mortality in the perioperative period; Botto et al. reported that myocardial injury consecutive to ischemia is associated with substantial 
per- and post-operative mortality in adults undergoing noncardiac surgery [39]. The pathophysiology of perioperative myocardial ischemia is complex, including surgical stress, pain, prothrombotic status, and hypersympathetic tonus, leading to mismatch between myocardial oxygen supply and demand [40]. Of note, the occurrence of some intraoperative events (i.e., blood transfusion, a fall more than $20 \mathrm{mmHg}$ in mean arterial blood pressure for more than 60 consecutive minutes, persistent tachycardia in the recovery room [>30 bpm from baseline for more than 5 consecutive min] predisposes to cardiac complications, namely, myocardial ischemia) [41].

The occurrence of myocardial ischemia may be asymptomatic in the post-operative period, or may manifest as angina, or even may manifest as complications of ischemia/infarction such as heart failure. The clinical manifestation of myocardial ischemia such as angina in this context is typically minimal, given that it may occur peroperatively or even postoperatively when the patient is still under the effect of sedation, or even taking antalgics as regular postoperative medication [39]. Troponin measurement up to 3 days after noncardiac surgery is of utmost importance to monitor the occurrence of myocardial ischemia in high-risk patients [39].

Adequate patient preparation and customized perioperative hydration are essential, namely, in patients already known to have coronary artery disease, medications management, introduction of protective agents (i.e., nitrates, beta-blockers, etc.) is made on a case-by-case decision [39], [42]. Pre-operative cardiac tests are recommended only if test results are expected to change perioperative management, and they may consist, besides the baseline EKG, of stress test, stress echo, or even coronary angiography [43], [44], [45].

\section{Valvular heart disease}

Aortic and mitral valve diseases are the most common valvular diseases encountered during the perioperative assessment, and significant valvular heart disease is recognized as a risk factor for increased morbidity in noncardiac surgery [8], [46]. Echocardiogram is indicated preoperatively in every patient suspected or known to have valvular heart disease to assess its type and severity [47]. When assessing valvular heart disease, whether related to native or prosthetic valves, three main considerations are essential in this context: Type and severity of valvular disease, management of medications (i.e., anticoagulation), and prophylaxis of endocarditis [48].

Among all valvular heart diseases, aortic stenosis, especially when severe, is associated with the greatest operative and post-operative risk, and anesthesiologist should proceed with special considerations in this regard [49]. Appropriate antibiotic prophylaxis reduces the risk of infective endocarditis in patients with native or prosthetic valve disease, also anticoagulation must be adequately managed in the perioperative period, especially in patients with mechanical valve prosthesis [50]. In general, valvular heart disease and resulting comorbidities, such as heart failure or atrial fibrillation, significantly increase the risk for perioperative adverse events; accordingly, appropriate perioperative assessment, monitoring, and management is essential.

\section{Arrhythmia}

Cardiac arrhythmias are frequently encountered during the perioperative period, also documented pre-operative arrhythmias is associated with higher prevalence of intraoperative and postoperative arrhythmias [51]. Arrhythmia may occur even in the absence of cardiac condition and it may simply result from the hyperadrenergic status, hypoxia, hypovolemia, electrolyte disturbance, acidosis, or hypothermia encountered during the perioperative period [52], [53]. Arrhythmia prevention in the perioperative period is based on avoidance or reduction of excessive sympathetic stimulation consecutive to pain or stress; in this regard, adequate sedation along with medication management (i.e., beta-blockers) is helpful [54].

Some arrhythmias - such as left bundle branch block or atrial fibrillation - represent an independent predictor of post-operative adverse events; in this context, advanced cardiac testing (Holter, echocardiogram...) must be considered for assessment, also medications management is essential for prevention and management of perioperative dysrhythmic risk [55], [56]. Postoperative monitoring is essential in all patients estimated at high risk of malignant ventricular arrhythmia such as ventricular tachycardia or fibrillation [53]. Of note, any heart conduction disease noticed preoperatively, may progress to more advanced conduction block during the intra- or post-operative period, and in such conditions, close monitoring or even prophylactic pacing may be required on a case by case decision [57], [58].

Patients with pacemakers or implantable cardioverter-defibrillators need special attention; they must have their devices checked preoperatively, and sometimes per- and postoperatively, also the surgeon and anesthesiologist should be informed about the presence of cardiac electronic implantable device. Of note, electric cauterization is usually prohibited in this setting; nevertheless, its use is decided on a case by case decision after approval of the electrophysiologist [59], [60], [61]. Figure 4 summarizes the required data and cautions to undertake in patients with a cardiac electronic implantable device. 


\begin{tabular}{|c|c|}
\hline Data and measures & Cautions/To-do \\
\hline $\begin{array}{l}\text { Preoperative period: } \\
\text { - Intended surgical procedure, location of CEID } \\
\text { - interrogation mandatory: } \\
\text { type of CEID (PM or ICD) } \\
\text { check for dependency }\end{array}$ & $\begin{array}{l}\text { Cardiothoracic or chest wall surgical } \\
\text { procedure could impair/displace CIED generator or leads } \\
\text { Temporary programming may be required, } \\
\text { Temporary pacemaker may be required, } \\
\text { Give advice regarding use of electrocautery }\end{array}$ \\
\hline $\begin{array}{l}\text { Peroperative period: } \\
\text { - keep available personnel and tools } \\
\text { - use of electrocautery and type }\end{array}$ & $\begin{array}{l}\text { Permanent monitoring } \\
\text { External defibrillator standby, keep available magnet/ Programmer, } \\
\text { Availability of Industry Allied Professional and/or Electrophysiologist, } \\
\text { Electrocautery very close to the CEID is prohibited; Bipolar } \\
\text { electrocautery could be applied far from CEID, on a case-by-case } \\
\text { decision, under monitoring and after Electrophysiologist approval }\end{array}$ \\
\hline $\begin{array}{l}\text { Postoperative period: } \\
\text { - Consider re-interrogation and } \\
\text { reprogrammation of CEID }\end{array}$ & $\begin{array}{l}\text { Anticipated post-procedural monitoring or telemetry for special } \\
\text { subsets of patients }\end{array}$ \\
\hline
\end{tabular}

Figure 4: Data to acquire and cautions to undertake in patients with a cardiac electronic implantable device (adapted from Stone et al. [60]). CEID: Cardiac electronic implantable device, PM: Pacemaker, ICD: Implantable cardioverter-defibrillator

\section{Cardiac medications management}

The use of statins in the perioperative period is controversial; however, it should be continued in patients already taking such medications given the beneficial effect related to the pleiotropic property of these drugs [62]. To avoid the adverse events of the bedridden status and hypercoagulation risk, antithrombotics are indicated in almost every patient in the perioperative period.

Patients with previous cardiac conditions who are taking anti-platelets or anticoagulants should be adequately managed while weighing risks and benefits of bridging to low molecular weight heparin [63], [64], [65]. In patients with coronary stents, the individual thrombotic and hemorrhagic risks must be evaluated; however, elective noncardiac surgery is preferably performed at least 6 months after coronary stenting. Rossini et al. reported that Aspirin may be continued perioperatively in the majority of patients with coronary stents, also in patients with low risk of bleeding, dual antiplatelet therapy should not be withdrawn [42]. However, if bleeding risk is significant and antiplatelet therapy is stopped, perioperative therapy with shortacting intravenous glycoprotein Ilb/llla inhibitors should be taken into consideration [42].

The hypersympathetic activity in the perioperative period, related to fear, pain, and surgical stress results in tachycardia, vasoconstriction, and hypercoagulable status. Patients on beta-blocker therapy are usually kept on this beneficial therapy, also some patients (i.e., those with baseline tachycardia) may benefit from beta-blockers therapy given their perioperative benefit related to a decreased morbidity and mortality [66], [67]. Antibioprophylaxis is useful in the perioperative period in patients with valvular heart disease in order to minimize the risk of infectious endocarditis [46].

\section{Role of Anesthesiologist and insight into perioperative care}

While the cardiologist has the main role to assess cardiac condition and to prevent cardiovascular complications, the anesthesiologist has the broader role to assess all the patient general condition, also to require interdisciplinary cooperation whenever necessary to optimize pre-existing disorders, and to lower the general perioperative risk [68]. Figure 5 illustrates the different steps of the process that is usually followed in the chain from initial patient consultation until surgical procedure.

The role of the anesthesiologist is essential, it extends from the pre-operative evaluation, to operative anesthesia technique and to post-operative management. The anesthesia technique starts with premedication which is important to reduce surgical stress, followed by effective intraprocedural anesthesia, then the recovery (awakening) from anesthesia [69]. In the pre-operative phase, the anesthesiologist has to estimate the global surgical risk; in this respect, all systems are overviewed, namely, respiratory, renal, and endocrine system, also functional capacity is evaluated. Of note, a metabolic equivalent (MET) $\leq 3$ represents a 


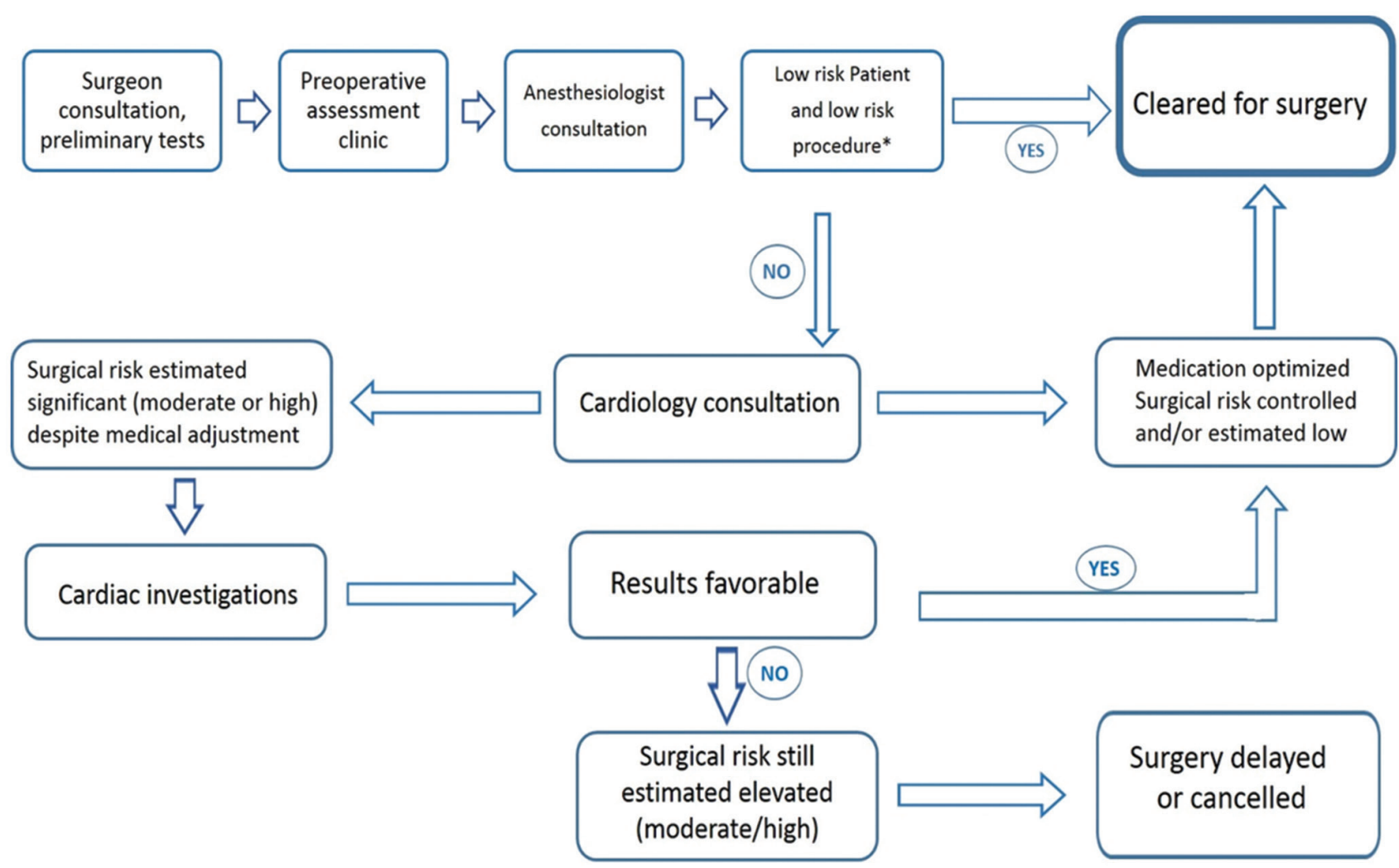

Figure 5: Algorithm showing the different steps of the process that is usually followed in the chain from initial patient consultation until surgical procedure. EKG: Electrocardiogram, CXR: Chest $X$ rays

poor functional capacity and is considered a significant pre-operative risk factor [70].

Anesthesia techniques include general anesthesia, neuraxial techniques, regional anesthesia, and monitored anesthesia care. During surgery, there are many changes that occur in the organism, these changes comprise mainly hemodynamic, endocrine, and metabolic aspects, and they can be a reaction to surgical stress or consecutive to anesthetic agents, to endotracheal intubation, and to perioperative fluid imbalance and potential blood loss [71]. In all cases, it is essential to implement a customized anesthetic technique according to the patient's condition. It is important to remember that stress response to surgery is a kind of physiological reaction and therefore, total suppression of the endocrine stress response may be hazardous [71]. Similarly, a substantial neuroendocrine reaction during surgery may result in hemodynamic dysfunction, namely, in patients with heart failure [71].

Stress response is modulated during surgery according to the type of anesthesia and type of agents used; for instance, with local anesthesia, there is an afferent blockade, whereas with general anesthesia, there is central modulation. Neuraxial anesthesia includes spinal and epidural anesthesia, and it yields a lower stress response due to sympathetic nerve blockage, provoking vasodilation, and sometimes significant hypotension. Nevertheless, when compared to general anesthesia, neuraxial anesthesia is associated with lower morbidity and mortality, especially in high-risk patients [72]. However, neuraxial anesthesia may be harmful in patients with severe aortic stenosis, where significant peripheral vasodilatation may worsen the hemodynamic status [73]

Post-operative pain engenders a physiological stress response that incorporates an increased heart rate, stroke volume, and peripheral resistance due to enhanced sympathetic activity. All these changes will increase myocardial work and oxygen demand. Accordingly, different pain management regimens are available such as classical antalgics alone or in association with non-steroidal anti-inflammatory drugs, intravenous opioids, or neuraxial analgesia [74]. Of note, noncardiac post-operative complications are usually managed by the anesthesiologist; among these, pulmonary complications are relatively frequent; older age, longer procedure duration, and pre-existent pulmonary conditions are risk factors for post-operative pulmonary complications [75].

\section{Practical and clinical implications}

In general, pre-operative cardiac assessment should focus primarily on an evaluation of the current cardiac condition for the impending surgery, along with a global overview of the long-term cardiovascular risk factors. Cardiologists should avoid systematic use of some terminology (i.e., "cleared for surgery") during 
the pre-operative consultation, they should rather stratify patients into low, moderate, or high risk. Of note, cardiology consultations that occur few minutes before elective surgical procedure (last minutes cardiology consultations) are often consecutive to lack of organizational issues and must be avoided given that they do not ensure optimal patient assessment and preparation in such context [68]. Moreover, patients with moderate or high surgical risk score often require an integrated and multidisciplinary approach to ensure a tailored preparation and optimal surgical outcome [68]. Of note, early detection of cardiovascular post-operative complications is essential to decrease morbidity and mortality in the post-operative period; in this regard, BNP and troponin serial measurements in high-risk patients in the post-operative period showed high sensitivity to predict post-operative complications [76], [77].

Perioperative risk estimation comprises multiple facets, including general clinical status, risk scores, biomarkers, functional capacity, type of surgery, and intraoperative technique and post-operative monitoring and management. High-risk cardiac patients usually remain vulnerable in the immediate post-operative period and accordingly, electrical and hemodynamic monitoring is justified during this period [78]. In general, the implementation of targeted and tailored diagnostic and management strategies allow to reduce the perioperative morbidity and mortality. Professional practice should be systematically evaluated and re-evaluated to improve clinical outcome and to decrease unnecessary expenses, especially in healthcare systems where budgets are often restricted.

\section{Conclusion}

During the pre-operative period, attention to the presence, nature, and severity of any cardiac condition allows appropriate perioperative monitoring and management. Coronary artery disease, hypertension, arrhythmia, valvular heart disease, and heart failure constitute the main cardiac conditions that must be recognized and managed in the perioperative period. The assessment of cardiac risk using validated scores is useful and should be implemented more frequently in daily practice. Implementation of diagnostic, preventive, or therapeutic medical strategies is based on the individual clinical setting and must be tailored to minimize the risk of perioperative cardiac morbidity and mortality. The era when a single man (i.e., surgeon) could significantly impact the perioperative outcome is definitively obsolete, and nowadays, a multidisciplinary approach, consisting of a joint effort by all health-care personnel, along with hospital managers can result in a clinically significant and favorable perioperative outcome.

\section{References}

1. Messinne J. A preoperative consultation. Tech Hosp Med Soc Sanit. 1959;14(162):44

2. Mullendore JM. Pre-operative consultations in organic voice disorders. Va Med Mon (1918). 1955;82(3):141-3. PMid: 14359713

3. Goldman L, Caldera DL, Nussbaum SR, Southwick FS, Krogstad D, Murray B, et al. Multifactorial index of cardiac risk in noncardiac surgical procedures. NEngl J Med. 1977;297(16):84550. https://doi.org/10.1056/nejm197710202971601 PMid:904659

4. Furuichi $\mathrm{Y}$, Sakamoto A. Perioperative cardiovascular evaluation and management for noncardiac surgery. Masui. 2014;63(3):287-95

PMid:24724438

5. Flood C, Fleisher LA. Preparation of the cardiac patient for noncardiac surgery. Am Fam Physician. 2007;75(5):656-65.

PMid:17375511

6. Fleisher LA, Beckman JA, Brown KA, Calkins H, Chaikof E, Fleischmann KE, et al. ACC/AHA 2007 guidelines on perioperative cardiovascular evaluation and care for noncardiac surgery: executive summary: A report of the American college of cardiology/American Heart association task force on practice guidelines. J Am Coll Cardiol. 2007;50(17):1707-32. https://doi. org/10.3410/f.1108557.564633

PMid:17950159

7. Rao JY, Yeriswamy MC, Santhosh MJ, Shetty GG, Varghese K, Patil CB, et al. A look into LEE's score: Peri-operative cardiovascular risk assessment in noncardiac surgeries-usefulness of revised cardiac risk index. Indian Heart J. 2012;64(2):134-8. https://doi.org/10.1016/ s0019-4832(12)60047-9

PMid:22572486

8. Kristensen SD, Knuuti J, Saraste A, Anker S, Bøtker HE, De Hert S, et al. 2014 ESC/ESA Guidelines on non-cardiac surgery: Cardiovascular assessment and management: The Joint Task Force on non-cardiac surgery: Cardiovascular assessment and management of the European society of cardiology (ESC) and the European society of anaesthesiology (ESA). Eur $\mathrm{J}$ Anaesthesiol. 2014;31(10):517-73. https://doi.org/10.1093/ eurheartj/ehu282

PMid:25127426

9. Landoni G, Pasin L, Monti G, Cabrini L, Beretta L, Zangrillo A. Towards zero perioperative mortality. Heart Lung Vessel. 2013;5(3):133-6.

PMid:24364003

10. Wijeysundera DN, Austin PC, Beattie WS, Hux JE, Laupacis A Outcomes and processes of care related to preoperative medical consultation. Arch Intern Med. 2010;170(15):1365-74. https://doi.org/10.1001/archinternmed.2010.204 PMid:20696963

11. Halm EA, Browner WS, Tubau JF, Tateo IM, Mangano DT Echocardiography for assessing cardiac risk in patients having noncardiac surgery. Study of peri-operative Ischemia research group. Ann Intern Med. 1996;125(6):433-41. https://doi. org/10.7326/0003-4819-125-6-199609150-00001 PMid:8779454

12. Fischer MO, Le Manach $\mathrm{Y}$. Perioperative medicine: From theorical guidelines to clinical practice. Anaesth Crit Care Pain Med. 2016;35(4):241-2. https://doi.org/10.1016/j. accpm.2016.06.002

PMid:27475829 
13. Grocott MP, Plumb JO, Edwards M, Fecher-Jones I, Levett DZ. Re-designing the pathway to surgery: Better care and added value. Perioper Med (Lond). 2017;6:9. https://doi.org/10.1186/ s13741-017-0065-4

PMid:28649376

14. Glance LG, Lustik SJ, Hannan EL, Osler TM, Mukamel DB, Qian $\mathrm{F}$, et al. The surgical mortality probability model: Derivation and validation of a simple risk prediction rule for noncardiac surgery. Ann Surg. 2012;255(4):696-702. https://doi. org/10.1097/sla.0b013e31824b45af PMid:22418007

15. Wirthlin DJ, Cambria RP. Surgery-specific considerations in the cardiac patient undergoing noncardiac surgery. Prog Cardiovasc Dis. 1998;40(5):453-68. https://doi.org/10.1016/ s0033-0620(98)80017-0 PMid:9585377

16. Ford MK, Beattie WS, Wijeysundera DN. Systematic review: Prediction of perioperative cardiac complications and mortality by the revised cardiac risk index. Ann Intern Med. 2010;152(1):2635. https://doi.org/10.7326/0003-4819-152-1-201001050-00007 PMid:20048269

17. Maisel AS, Bhalla V, Braunwald E. Cardiac biomarkers: A contemporary status report. Nat Clin Pract Cardiovasc Med. 2006;3(1):24-34.

PMid:16391615

18. Priebe HJ. Peri-operative myocardial infarction: Aetiology and prevention. Br J Anaesth. 2005;95(1):3-19. PMid:15665072

19. Guay J, Choi P, Suresh S, Albert N, Kopp S, Pace NL. Neuraxial blockade for the prevention of post-operative mortality and major morbidity: An overview of Cochrane systematic reviews. Cochrane Database Syst Rev. 2014;1:CD010108. https://doi. org/10.1002/14651858.cd010108.pub2 PMid:24464831

20. Detsky AS, Abrams HB, Forbath N, Scott JG, Hilliard JR. Cardiac assessment for patients undergoing noncardiac surgery. A multifactorial clinical risk index. Arch Intern Med. 1986;146(11):2131-4. https://doi.org/10.1001/ archinte.146.11.2131

PMid:3778043

21. Lee TH, Marcantonio ER, Mangione CM, Thomas EJ, Polanczyk CA, Cook EF, et al. Derivation and prospective validation of a simple index for prediction of cardiac risk of major noncardiac surgery. Circulation. 1999;100(10):1043-9. https:// doi.org/10.1161/01.cir.100.10.1043

PMid:10477528

22. Gupta PK, Gupta H, Sundaram A, Kaushik M, Fang X, Miller WJ, et al. Development and validation of a risk calculator for prediction of cardiac risk after surgery. Circulation. 2011;124(4):381-7. https://doi.org/10.1161/circulationaha.110.015701

PMid:21730309

23. Aresti NA, MalikAA, Ihsan KM, Aftab SM, Khan WS. Perioperative managementofcardiac disease. JPerioperPract. 2014;24(1-2):914. https://doi.org/10.1177/1750458916024001-202 PMid:24516966

24. Kirkham KR, Wijeysundera DN, Pendrith C, Ng R, Tu JV, Laupacis $\mathrm{A}$, et al. Preoperative testing before low-risk surgical procedures. CMAJ. 2015;187(11):E349-58. https://doi. org/10.1503/cmaj.150174

PMid:26032314

25. Maddox TM. Preoperative cardiovascular evaluation for noncardiac surgery. Mt Sinai J Med. 2005;72(3):185-92. PMid: 15915313

26. Weber M, Luchner A, Seeberger M, Mueller C, Liebetrau C,
Schlitt $A$, et al. Incremental value of high-sensitive troponin $\mathrm{T}$ in addition to the revised cardiac index for peri-operative risk stratification in non-cardiac surgery. Eur Heart J. 2013;34(11):853-62. https://doi.org/10.1093/eurheartj/eht129 PMid:23257946

27. Dernellis J, Panaretou M. Assessment of cardiac risk before noncardiac surgery: Brain natriuretic peptide in 1590 patients. Heart. 2006;92(11):1645-50. https://doi.org/10.1136/hrt.2005.085530 PMid:16709695

28. Rohde LE, Polanczyk CA, Goldman L, Cook EF, Lee RT, Lee TH. Usefulness of transthoracic echocardiography as a tool for risk stratification of patients undergoing major noncardiac surgery. Am J Cardiol. 2001;87(5):505-9. https://doi.org/10.1016/ s0002-9149(00)01421-1

PMid:11230829

29. Mori F, Zuppiroli A. Preoperative cardiovascular assessment in non-cardiac surgery: The role of non-invasive procedures. Ital Heart J Suppl. 2003;4(1):19-27.

PMid:12690930

30. Howell SJ, Sear JW, Foex P. Hypertension, hypertensive heart disease and peri-operative cardiac risk. $\mathrm{Br} \mathrm{J}$ Anaesth. 2004;92(4):570-83.

PMid: 15013960

31. Wallace AW, Au S, Cason BA. Association of the pattern of use of peri-operative beta-blockade and post-operative mortality. Anesthesiology. 2010;113(4):794-805. https://doi.org/10.1097/ aln.0b013e3181f1c061

PMid:20864832

32. Mosterd A, Hoes AW. Clinical epidemiology of heart failure. Heart. 2007;93(9):1137-46. https://doi.org/10.1136/hrt.2003.025270 PMid: 17699180

33. Healy KO, Waksmonski CA, Altman RK, Stetson PD, Reyentovich $\mathrm{A}$, et al. Peri-operative outcome and long-term mortality for heart failure patients undergoing intermediate- and high-risk noncardiac surgery: Impact of left ventricular ejection fraction. Congest Heart Fail. 2010;16(2):45-9. https://doi. org/10.1111/j.1751-7133.2009.00130.x

PMid:20412467

34. Xu-Cai YO, Brotman DJ, Phillips CO, Michota FA, Tang WH, Whinney $\mathrm{CM}$, et al. Outcomes of patients with stable heart failure undergoing elective noncardiac surgery. Mayo Clin Proc. 2008;83(3):280-8. https://doi.org/10.4065/83.3.280 PMid: 18315993

35. Meta-Analysis Global Group in Chronic Heart Failure. The survival of patients with heart failure with preserved or reduced left ventricular ejection fraction: An individual patient data meta-analysis. Eur Heart J. 2012;33(14):1750-7. https://doi. org/10.1093/eurheartj/ehr254

PMid:21821849

36. Hammill BG, Curtis LH, Bennett-Guerrero E, O'Connor CM, Jollis JG, Schulman KA, et al. Impact of heart failure on patients undergoing major noncardiac surgery. Anesthesiology. 2008;108(4):559-67. https://doi.org/10.1097/ aln.0b013e31816725ef

PMid:18362586

37. Navarro LH, Bloomstone JA, Auler JO Jr., Cannesson, M., Rocca GD, Gan TJ, et al. Perioperative fluid therapy: A statement from the international Fluid Optimization Group. Perioper Med (Lond). 2015;4:3. https://doi.org/10.1186/s13741-015-0014-z PMid:25897397

38. McMurray JJ, Adamopoulos S, Anker SD, Auricchio A, Böhm M, Dickstein $\mathrm{K}$, et al. ESC guidelines for the diagnosis and treatment of acute and chronic heart failure 2012: The task force for the diagnosis and treatment of acute and chronic heart failure 2012 of the European society of cardiology. Developed 
in collaboration with the heart failure association (HFA) of the ESC. Eur J Heart Fail. 2012;33(14):803-69. https://doi.org/10.3 410/f.718489795.793497182

\section{PMid:22611136}

39. Botto F, Alonso-Coello P, Chan MT, Villar JC, Xavier D Srinathan S, et al. Myocardial injury after noncardiac surgery: A large, international, prospective cohort study establishing diagnostic criteria, characteristics, predictors, and 30-day outcomes. Anesthesiology. 2014;120(3):564-78. https://doi.org /10.3410/f.718281315.793491697 PMid:24534856

40. Szczeklik W, Devereaux PJ. Troponin T level and mortality risk after noncardiac surgery: Practical implications of the VISION study. Pol Arch Med Wewn. 2012;122(10):499-503. https://doi. org/10.20452/pamw.1421

PMid:23123527

41. Biccard BM, Rodseth RN. What evidence is there for intraoperative predictors of perioperative cardiac outcomes? A systematic review. Perioper Med (Lond). 2013;2(1):14. https:// doi.org/10.1186/2047-0525-2-14

PMid:24472327

42. Rossini R, Musumeci G, Visconti LO, Bramucci E, Castiglioni B, De Servi S, et al. Perioperative management of antiplatelet therapy in patients with coronary stents undergoing cardiac and non-cardiac surgery: A consensus document from Italian cardiological, surgical and anaesthesiological societies. Eurolntervention. 2014;10(1):38-46. https://doi.org/10.4244/ eijv10i1a8

\section{PMid:24832636}

43. Pannell LM, Reyes EM, Underwood SR. Cardiac risk assessment before non-cardiac surgery. Eur Heart J Cardiovasc Imaging. 2013;14(4):316-22. https://doi.org/10.1093/ehjci/jes288 PMid:23288896

44. Older P. Anaerobic threshold, is it a magic number to determine fitness for surgery? Perioper Med (Lond). 2013;2(1):2. https:// doi.org/10.1186/2047-0525-2-2

PMid:24472514

45. Wolk MJ, Bailey SR, Doherty JU, Douglas PS, Hendel RC Kramer CM, et al. ACCF/AHA/ASE/ASNC/HFSA/HRS/SCAI/ SCCT/SCMR/STS 2013 multimodality appropriate use criteria for the detection and risk assessment of stable ischemic heart disease. J Am Coll Cardiol. 2014;63(4):380-406. https://doi. org/10.1016/j.jacc.2013.11.009

PMid:24355759

46. Bach DS, Eagle KA. Perioperative assessment and management of patients with valvular heart disease undergoing noncardiac surgery. Minerva Cardioangiol. 2004;52(4):255-61. PMid:15284676

47. Vahanian A, Alfieri O, Andreotti F, Barón-Esquivias G, Baumgartner $\mathrm{H}$, Borger MA, et al. Guidelines on the management of valvular heart disease (version 2012): The joint task force on the management of valvular heart disease of the European society of cardiology (ESC) and the European association for cardiothoracic surgery (EACTS). Eur Heart J. 2012;33(19):2451-96. https://doi.org/10.3410/f.718396448.793499638

PMid:22922415

48. Markovi D, Janković R, Kovadević-Kostić N, Velinović M, Vranes M, Ivanović B, et al. The preoperative assessment of patients with valvular heart disease as a comorbidity. Acta Chir lugosl. 2011;58(2):31-7. https://doi.org/10.2298/aci1102031m PMid:21879648

49. Frogel J, Galusca D. Anesthetic considerations for patients with advanced valvular heart disease undergoing noncardiac surgery. Anesthesiol Clin. 2010;28(1):67-85. https://doi. org/10.1016/j.anclin.2010.01.008

\section{PMid:20400041}

50. Nishimura RA, Carabello BA, Faxon DP, Freed MD, Lytle BW, Patrick T, et al. ACC/AHA 2008 Guideline update on valvular heart disease: Focused update on infective endocarditis. J Am Coll Cardiol. 2008;52(8):676-85. https://doi.org/10.1016/j. jacc.2008.05.008

PMid: 18702976

51. Brathwaite $D$, Weissman $C$. The new onset of atrial arrhythmias following major noncardiothoracic surgery is associated with increased mortality. Chest. 1998;114(2):462-8. https://doi. org/10.1378/chest.114.2.462

PMid:9726731

52. Sueda T. Non-cardiac surgery for patients with arrhythmia. Nihon Geka Gakkai Zasshi. 2005;106(5):349-51. PMid: 15934553

53. Walsh SR, Tang T, Wijewardena C, Yarham SI, Boyle JR, Gaunt ME. Postoperative arrhythmias in general surgical patients. Ann R Coll Surg Engl. 2007;89(2):91-5. PMid:17346395

54. Kawano T, Oshita S. Preoperative evaluation and management of arrhythmia. Masui. 2010;59(7):854-7. PMid:20662284

55. Amar D. Strategies for perioperative arrhythmias. Best Pract Res Clin Anaesthesiol. 2004;18(4):565-77.

PMid: 15460546

56. Dorman T, Breslow MJ, Pronovost PJ, Rock P, Rosenfeld BA. Bundle-branch block as a risk factor in noncardiac surgery. Arch Intern Med. 2000;160(8):1149-52. https://doi.org/10.1001/ archinte.160.8.1149

PMid:10789608

57. Csontos C, Bogar L, Melczer L. Temporary pacemakers for noncardiac surgery. Eur J Anaesthesiol. 2003;20(7):581-2. https:// doi.org/10.1017/s0265021503240928 PMid:12884996

58. Boezaart AP, Clinton CW, Stanley A. Pre-operative prophylactic transvenous cardiac pacing for bifascicular heart block. S Afr J Surg. 1989;27(3):103-5. PMid:2762933

59. Kawano T, Oshita S. Preoperative assessment of patient with implanted cardiac pacemakers and defibrillators. Masui. 2010;59(7):858-61. PMid:20662285

60. Stone ME, Salter B, Fischer A. Perioperative management of patients with cardiac implantable electronic devices. $\mathrm{Br} \mathrm{J}$ Anaesth. 2011;107(1):i16-26. https://doi.org/10.1093/bja/aer354 PMid:22156267

61. American Society of Anesthesiologists. Practice advisory for the perioperative management of patients with cardiac implantable electronic devices: Pacemakers and implantable cardioverterdefibrillators: An updated report by the american society of anesthesiologists task force on perioperative management of patients with cardiac implantable electronic devices. Anesthesiology. 2011;114(2):247-61. https://doi.org/10.1097/ aln.0b013e3181fbe7f6

PMid:21245737

62. Chan WW, Wong GT, Irwin MG. Perioperative statin therapy. Expert Opin Pharmacother. 2013;14(7):831-42. PMid:23621829

63. Yurttas T, Wanner PM, Filipovic M. Perioperative management of antithrombotic therapies. Curr Opin Anaesthesiol. 2017;30(4):466-73. https://doi.org/10.1097/ aco.0000000000000481

PMid:28509773 
64. Brilakis ES, Banerjee S, Berger PB. Perioperative management of patients with coronary stents. J Am Coll Cardiol. 2007;49(22):2145-50.

PMid: 17543633

65. Alshawabkeh LI, Banerjee S, Brilakis ES. Systematic review of the frequency and outcomes of non-cardiac surgery after drugeluting stent implantation. Hellenic J Cardiol. 2011;52(2):141-8. PMid:21478124

66. Angeli F, Reboldi G, Verdecchia P. Good news for $\beta$-blockers in perioperative medicine. Expert Opin Drug Saf. 2011;10(4):4918. https://doi.org/10.1517/14740338.2011.560113 PMid:21609193

67. Daumerie G, Fleisher LA. Perioperative beta-blocker and statin therapy. Curr Opin Anaesthesiol. 2008;21(1):60-5. https://doi. org/10.1097/aco.0b013e3282f35ea5

PMid:18195612

68. Silverman DG, Rosenbaum SH. Integrated assessment and consultation for the preoperative patient. Med Clin North Am. 2009;93(5):963-77. https://doi.org/10.1016/j.mcna.2009.05.010 PMid:19942170

69. Prause G, List WF. The anesthesiologic risk patient. Preoperative evaluation, intraoperative management and postoperative monitoring. Chirurg. 1997;68(8):775-779.

PMid:9377987

70. Hlatky MA, Boineau RE, Higginbotham MB, Lee KL, Mark DB, Califf RM, et al. A brief self-administered questionnaire to determine functional capacity (the Duke Activity Status Index). Am J Cardiol. 1989;64(10):651-4. https://doi. org/10.1016/0002-9149(89)90496-7

\section{PMid:2782256}

71. Adams HA, Hempelmann G. The endocrine stress reaction in anesthesia and surgery--origin and significance. Anasthesiol Intensivmed Notfallmed Schmerzther. 1991;26(6):294-305. https://doi.org/10.1055/s-2007-1000587

PMid:1751650
72. Rodgers A, Walker N, Schug S, McKee A, Kehlet H, van Zundert $A$, et al. Reduction of post-operative mortality and morbidity with epidural or spinal anaesthesia: Results from overview of randomised trials. BMJ. 2000;321(7275):1493-7. https://doi.org/10.1136/bmj.321.7275.1493

\section{PMid:11118174}

73. Johansson S, Lind MN. Central regional anesthesia in patients with aortic stenosis: Systematic review. Dan Med J. 2017;64(9):A5407.

PMid:28874243

74. Liu SS, Wu CL. The effect of analgesic technique on postoperative patient reported outcomes including analgesia: A systematic review. Anesth Analg. 2007;105(3):789-808. https://doi.org/10.1213/01.ane.0000278089.16848.1e PMid:17717242

75. Kodra N, Shpata V, Ohri I. Risk factors for postoperative pulmonary complications after abdominal surgery. Open Access Maced J Med Sci. 2016;4(2):259-63. https://doi.org/10.3889/ oamjms.2016.059

PMid:27335597

76. Devereaux PJ, Chan MT, Alonso-Coello $\mathrm{P}$, Walsh $\mathrm{M}$, Berwanger $\mathrm{O}$, Villar JC, et al. Association between postoperative troponin levels and 30-day mortality among patients undergoing noncardiac surgery. JAMA. 2012;307(21):2295304. https://doi.org/10.1001/jama.2012.5502

77. Rodseth RN, Biccard BM, Chu R, Buse GA, Thabane L, Bakhai $A$, et al. Postoperative B-type natriuretic peptide for prediction of major cardiac events in patients undergoing noncardiac surgery: Systematic review and individual patient meta-analysis. Anesthesiology. 2013;119(2):270-83. https://doi. org/10.3410/f.717992281.793482133 PMid:23528538

78. Bose $\mathrm{S}$, Talmor D. Who is a high-risk surgical patient? Curr Opin Crit Care. 2018;24(6):547-53.

PMid:30308542 